\title{
Convergent Agency: Encouraging Transdisciplinary Approaches for Effective Climate Change Adaptation and Disaster Risk Reduction
}

\author{
América Bendito $^{1,2} \cdot$ Edmundo Barrios ${ }^{3}$
}

Published online: 5 December 2016

(C) The Author(s) 2016. This article is published with open access at Springerlink.com

\begin{abstract}
Three recent global agreements have been established to facilitate the implementation of global-level responsibilities to deal with disaster risk reduction (DRR), human development, and climate change adaptation (CCA) respectively. While these agreements have a common goal of reducing social, economic, and environmental vulnerability, they have been developed by largely independent communities of practice. This has limited cross-fertilization despite the inherent multidimensional nature of global challenges and the considerable thematic overlap. We argue that developing a transdisciplinary strategy that effectively integrates disciplines, approaches, and knowledge systems will lead to greater and more sustainable impacts, together with a more efficient use of financial resources. Hybrid approaches should be encouraged during planning of future development efforts so that risk reduction is conducted simultaneously with CCA. Transdisciplinary processes are central to generating contextsensitive knowledge to support decisions on CCA and DRR options that minimize trade-offs and maximize synergies and complementarities required to guide sustainable development trajectories. Finally, building codes together with climate and risk-smart research, education, and awareness raising, are identified as priority entry points to materialize the blending of DRR and CCA approaches and
\end{abstract}

América Bendito

americabendito@gmail.com

1 Department of Civil Engineering, Universidad de Los Andes, Mérida 5101-A, Venezuela

2 Independent Consultant, Nairobi, Kenya

3 World Agroforestry Centre (ICRAF), P.O. Box 30677-00100, Nairobi, Kenya effectively reduce risk while mitigating and adapting to climate change.

Keywords Building codes - Climate change adaptation - Disaster risk reduction - Sustainable development goals · Transdisciplinary knowledge

\section{Introduction}

For more than 25 years, the scientific community has been anticipating important global changes in the fields of climate change adaptation (CCA) and disaster risk reduction (DRR) following the release of the first assessment report of the Intergovernmental Panel on Climate Change (IPCC 1990). Since then a number of major global agreements and guidelines have taken place to address these issues (Fig. 1).

In 2015, three key global agreements were established to facilitate the implementation of global-level responsibilities to deal with DRR, human development, and CCA respectively (Fig. 1). In March, the Sendai Framework for Disaster Risk Reduction 2015-2030 (SFDRR) (UNISDR 2015) replaced the Hyogo Framework for Action 2005-2015 (HFA) (UNISDR 2005). The SFDRR was designed to guide the international community in its collective support of regions and countries in strengthening their resilience to disasters. In September, the Millennium Development Goals (MDGs) were replaced by the Sustainable Development Goals (SDGs) (UN 2015), where DRR was addressed by goals linked to poverty eradication, food security, infrastructure, cities and human settlements, climate change, and ecosystems. Finally, in December, at the 21st Session of the Conference of the Parties (COP 21) of the United Nations Framework Convention on Climate 

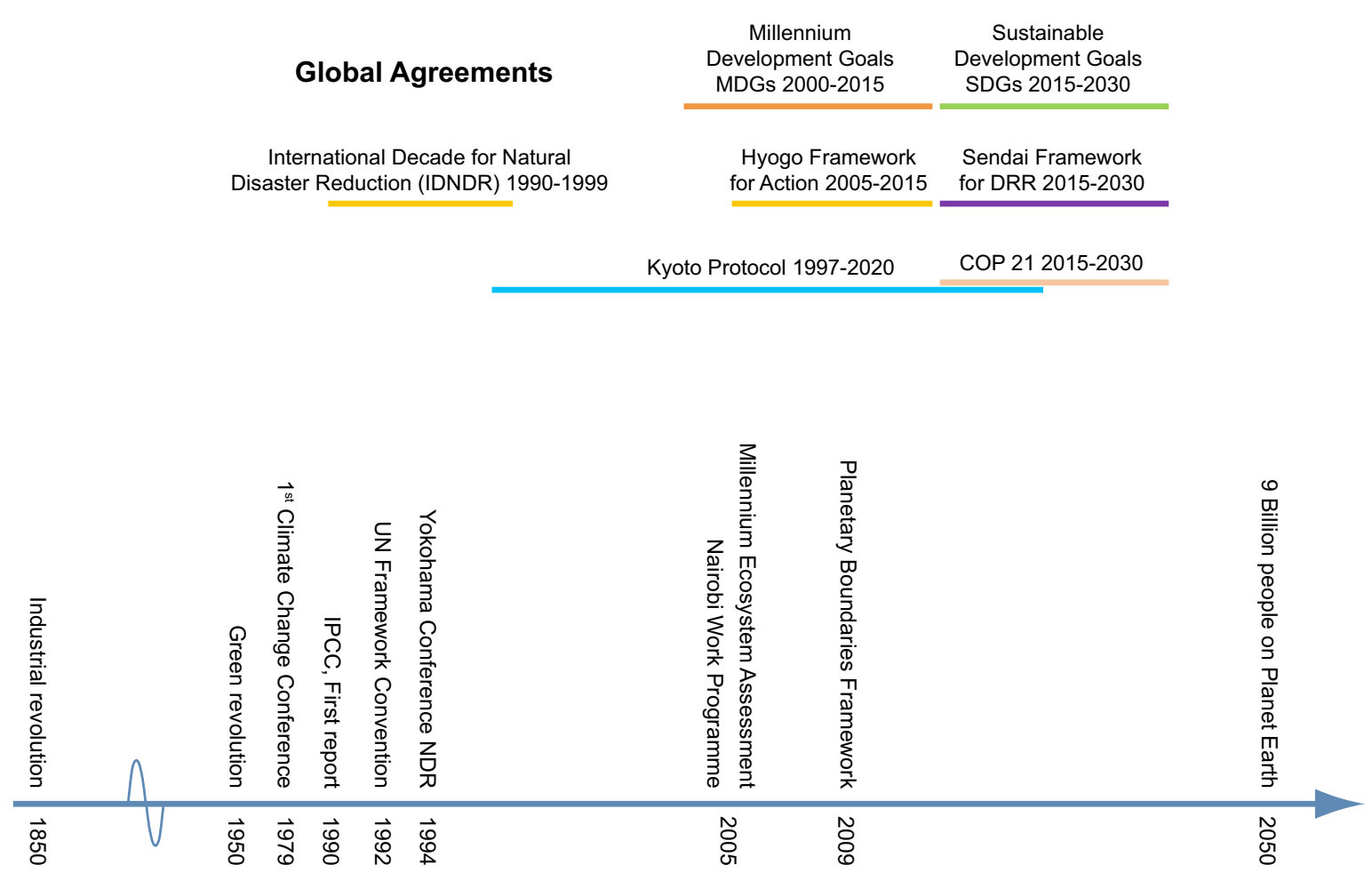

Fig. 1 Global initiatives in response to contemporary challenges on Planet Earth

Change (UNFCCC 2015), the draft of the Paris Agreement was adopted to address the immense challenges of climate change, hence facilitating government actions that encourage including risk reduction as part of efforts addressing CCA.

It is increasingly clear that these global efforts have overlapping goals. Developing a transdisciplinary strategy that effectively integrates disciplines, approaches, and knowledge systems will lead to greater and more sustainable impacts, together with a more efficient use of financial resources. This article briefly outlines areas of overlap, identifies priority entry points for collaborative engagement between the respective communities of practice, and proposes steps to guide the integration of DRR and CCA efforts to reduce vulnerability and increase their contribution to the SDGs.

\section{Transdisciplinary Knowledge Contributes to more Effective DRR and CCA Actions}

Developing transdisciplinary knowledge requires crossing multiple disciplinary boundaries, engaging scientific and nonscientific sources or practices, and using methodological tools that encourage collective learning (Barrios et al. 2012) from different disciplines to generate holistic understanding of global phenomena (Parkes et al. 2005; Stock and Burton 2011). In this section, we suggest a transdisciplinary process aimed at minimizing trade-offs, and maximizing synergies and complementarities between DRR and CCA efforts.

While efforts to reduce disaster risks and climate change risks have long coexisted, there is increasing recognition of the opportunities for blending CCA and DRR efforts because the types of actions required for both approaches are often similar (Doswald and Estrella 2015). Recognizing that climate change is a key hazard driver (Kelman 2015), for example, highlights the opportunity to explicitly incorporate the gradual effects of climate change when planning to reduce disaster risks.

When planning for DRR, traditional engineering options through structural approaches (reservoirs, dykes, seawalls, and dams), based on codes that do not take into account climate change, are normally the options considered. But when trying to adapt to climate change, ecosystem-based adaptation options are often considered, particularly in rural landscapes (Geneletti and Zardo 2016). We argue that both approaches should be strategically combined during planning of future development efforts so that adaptation to climate change is conducted simultaneously while reducing risks. The Dutch "Room for the River" program, ${ }^{1}$ established in response to the devastating 1993 and 1995 Rhine delta floods in the Netherlands, is a good example of combining DRR and CCA approaches that aims to give rivers

\footnotetext{
${ }^{1} \mathrm{https}: / / \mathrm{www}$. ruimtevoorderivier.nl/english/.
} 
space to flood safely in order to protect vulnerable urban and rural areas. The success of convergent agency, however, is dependent on the full recognition of the advantages and disadvantages of both approaches, over different temporal and spatial scales, in order to develop a transdisciplinary knowledge that minimizes trade-offs and maximizes synergies and complementarities. Encouraging a gradual and open process of cross-fertilization would foster convergence, limit the risk that results of one approach negatively affect the results of the other, and more importantly ensure that the resulting development actions will help to reduce, and not exacerbate, vulnerability.

The lack of transdisciplinary knowledge to support recovery plans to face disaster events misses a great opportunity for reducing vulnerability to hazards and increasing adaptation capacity in the longer term. In El Salvador, for example, people who lost their homes to Hurricane Mitch in 1998 were still living in temporary shelters when an earthquake struck in 2001, thus leaving them even more vulnerable than before (Wisner 2001). The wrong location of provisional settlements following a disaster can also lead to unplanned environmental problems (for example, deforestation) that could limit the contribution of natural ecosystems to CCA (Parker et al. 1995).

Similarly, while mangrove forests normally occupy the costal intertidal zones and have been shown to reduce the impact of tsunami events (Danielsen et al. 2005; EEA 2015), their replacement with unsuitable vegetation to presumably provide the same protective function may actually lead to greater damage. For example, the planting of pine forests to prepare for coastal natural events along Japan's coast exacerbated damage during the tsunami caused by the Great East Japan Earthquake in 2011. Pine trees are inadequate for such protective function given their characteristic shallow rooting pattern, are uprooted more easily, and become the first debris to hit and damage houses and other buildings (Renaud and Murti 2013). The replacement of mangrove forests would also have an impact on the functionality of aquatic ecosystems given their important role as breeding grounds for fish and nursery habitat for their juveniles (Kathiresan and Bingham 2001). The failure to blend relevant scientific knowledge and local knowledge and experience has been highlighted as a common limitation to matching tree-based interventions to variations in social-ecological context (Coe et al. 2014).

In contrast, The Nature Conservancy has used transdisciplinary knowledge to guide DRR actions in the case of 1-in-100 year storm events in New York City, and concludes that hybrid options offer the best protection from these storms, while also providing significant environmental benefits (Nature Conservancy 2015). Hybrid options combine biodiversity conservation with engineering options tailored for key habitats (dunes, mangroves, coral reefs, wetlands, and forests). They benefit from and do not disrupt the natural features of these habitats, thus lowering vulnerability by reducing wave energy, absorbing floodwaters, and helping defend against storms. Hybrid options can also be used in urban settings to help cope with the effects of increasing mean temperature associated with climate change. For example, increasing tree cover in cities by encouraging tree planting along streets, in parks and backyards, together with the naturalization of lands that surround water and water facilities, can play an important role in buffering temperature through shading and maintaining moist environments (Bowler et al. 2010). While hybrid options have shown significant potential, there is still limited practical evidence of their success in simultaneously addressing the impacts of DRR and CCA. This is likely the result of difficulties encountered in the attempt to fully embrace transdisciplinarity during knowledge sharing and integration processes across different disciplines, sectors, and scales relevant for ecosystem management and DRR (Scholz and Steiner 2015).

\section{The Strategic Role of Building Codes as an Entry Point to Reduce the Gap between CCA and DRR}

Building codes create uniform regulatory standards that hold design professionals and contractors responsible to a set of principles aimed to protect families, communities, and society at large in the event of a natural hazard (FEMA 2013). The absence of building codes, outdated building codes, and the failure to enforce existing codes, all represent a fundamental vulnerability issue in urban and rural areas. The importance of building codes was highlighted by the dramatic contrast between the impacts of recent earthquakes in Haiti, Chile, and Japan. While the Haiti 2010 earthquake generated considerable human and structural losses because of the lack of building codes, the reduced impact observed after the Chile 2010 and Japan 2011 earthquakes was the result of the successful implementation of building codes that reduced human and economic losses. While the Chile earthquake released nearly 1000 times more energy than the earthquake in Haiti, both in densely populated areas, it resulted in 1000 times fewer victims (Bendito and Gutiérrez 2015). It is worrisome that following the West Java, Indonesia 2009 earthquake, new building reconstruction efforts did not follow the existing building codes (EERI 2009), thus increasing vulnerability by neglecting the Sendai Framework's Priority 4 that emphasizes the need of "building back better to prevent creating new risks" (UNISDR 2015).

Building code challenges go beyond urban settings and can directly influence food security. Postharvest losses are 
recognized as one of the largest sources of inefficiency in agricultural production (IFAD 2013; CCAFS 2015). In Rwanda, for example, none of the postharvest facilities evaluated were designed with consideration of the emerging environmental and climate change challenges, nor were they constructed following building codes (Bendito and Twomlow 2014). While it is not viable to prevent selfconstruction, simple guidelines that include design, construction materials, and maintenance issues (Bendito and Twomlow 2014) can provide a significant contribution to transdisciplinary knowledge development processes that optimize hazard-resistance and ecosystem services in the self-constructed buildings.

Building codes should move from a passive to a proactive stance in order to maintain their relevance on a rapidly changing planet (Bendito and Gutiérrez 2015). Existing and new infrastructures should be better adapted to the current and expected future impacts of climate change. Building codes should therefore include, among other features, hazard maps developed for different events (multihazard maps) and for different engineering design levels (for example, differing return periods) (Bendito et al. 2014). Return period is the mean time between the occurrence of two specific hazards. Given the existing trend of increased frequency and intensity of climatic events, the current return periods (the probability of the most severe hazard event occurring in a 100-year period) used to develop hazard maps need to be revised to include shorter and multiple return periods.

Updated multihazard maps, data on exposure (building inventory, population size and distribution, soil types, and so on), ecosystem services (assessment of the degradation status of key habitats), Geographic Information Systems (GIS), and local knowledge (for example, early warning indicators) become critical components of risk maps as useful boundary objects during the development of transdisciplinary knowledge. Boundary objects are defined as collaborative products that can incorporate different points of view and still retain acceptable levels of robustness (Clark et al. 2011). Risk maps facilitate the communication of the spatial and temporal impacts of disasters on people, infrastructure, and ecosystem services by showing areas at high, medium, and low risk. Risk maps help to guide the development of mitigation and adaptation measures at different scales (for example, community, district, and national levels).

\section{Transdisciplinary Knowledge to Reduce Gaps between DRR and CCA}

The way in which findings are communicated in the global development arena can significantly influence outcomes because "words used are constructors of reality" (Mires
2015). If we continue to refer to human-made disasters as "natural disasters" people will continue to think that these disasters are acts of God and not caused by the increased vulnerability to hazards resulting from human actions. It is necessary to shift the perspective from natural disasters to "natural hazards" (Briceño 2015). We also have to make sure that these concepts exist globally in all cultures. In some African languages, for example, the term "risk", does not exist (Manyena 2016).

Developing transdisciplinary concepts that cut across the divides that mark traditional disciplinary boundaries can facilitate knowledge sharing and unification (Stock and Burton 2011). The Eco-Disaster Risk Reduction/Climate Change Adaptation (Eco-DRR/CCA) approach (Renaud et al. 2016) could be considered an effort to develop transdisciplinary knowledge. The Eco-DRR/CCA approach encourages the development of hybrid options by fostering the holistic thinking required to address complex problems synthesized in the SDGs. For example, when SDG 13 (Target 13.1) "strengthening resilience and adaptive capacity to climate-related hazards" is tackled using the Eco-DRR/CCA approach, Target 11.5 "reducing losses caused by disasters" and Target 6.6 "protect and restore water-related ecosystems, including mountains, forests, wetlands, rivers, aquifers and lakes" would also be directly influenced. Similarly, implementation of climate-smart postharvest projects as part of Eco DRR/CCA actions can simultaneously contribute to SDG 2 concerned with food security and improved nutrition, and SDG 9 concerned with building resilient infrastructure to foster sustainable development.

\section{Conclusion}

It is argued that DRR and CCA should be strategically combined during planning of future development efforts so that risk reduction is conducted simultaneously with adaptation to climate change. The ability of society to deal sensibly with risk and climate change, which largely occur together in time and space, would be strengthened with greater understanding of interactions between both phenomena. The value of transdisciplinary processes is shown to be central to research that generates context-sensitive knowledge to support decisions on CCA and DRR options that minimize trade-offs and maximize synergies and complementarities required to guide sustainable development trajectories.

Building codes are identified as a priority entry point to integrating DRR and CCA approaches. Climate- and risksmart education and awareness raising should also be a fundamental component of the strategy to face our 
increasingly unpredictable and challenging future. Universities need to improve undergraduate education teaching students to act locally while thinking globally, encouraging respect for diversity and the value of "deeper digging" through dialog and consensus building to fully benefit from processes of cross-fertilization. New engineering curricula need to seriously incorporate ecological knowledge as a resource rather than a burden, highlighting, for example, the strategic value of key habitats that act as natural solutions to reducing risk and vulnerability. Engineers would greatly benefit from a better understanding of the role of ecosystems and the multiple benefits they provide to society (ecosystem services) as great opportunities for convergent agency.

Acknowledgements We are grateful to Sálvano Briceño, Stephen Twomlow, and Arnaldo Gutiérrez for valuable comments that helped to improve this article. Funding to Edmundo Barrios to contribute to this article was partly provided by the CGIAR research programs on Forests, Trees and Agroforestry (FTA).

Open Access This article is distributed under the terms of the Creative Commons Attribution 4.0 International License (http://crea tivecommons.org/licenses/by/4.0/), which permits unrestricted use, distribution, and reproduction in any medium, provided you give appropriate credit to the original author(s) and the source, provide a link to the Creative Commons license, and indicate if changes were made.

\section{References}

Barrios, E., H.L.C. Coutinho, and C.A.B. Medeiros. 2012. InPaC-S: Participatory knowledge integration on indicators of soil quality-Methodological guide. Nairobi: World Agroforestry Centre (ICRAF), Embrapa, and International Center for Tropical Agriculture (CIAT). http://www.worldagroforestry.org/down loads/publications/PDFs/B17459.PDF. Accessed 8 April 2016.

Bendito, A., and A. Gutiérrez. 2015. Can building codes stop the vicious cycle of recurrent disaster? The Open Civil Engineering Journal 9: 226-235.

Bendito, A., J. Rozelle, and D. Bausch. 2014. Assessing potential earthquake loss in Mérida State, Venezuela using Hazus. International Journal of Disaster Risk Science 5(3): 176-191.

Bendito, A., and S. Twomlow. 2014. Promoting climate-smart approaches to postharvest challenges in Rwanda. International Journal of Agricultural Sustainability 13(3): 222-239.

Bowler, D.E., L. Buyung-Ali, T.M. Knight, and A.S. Pullin. 2010. Urban greening to cool towns and cities: A systematic review of the empirical evidence. Landscape and Urban Planning 97(3): 147-155.

Briceño, S. 2015. Looking back and beyond Sendai: 25 years of international policy experience on disaster risk reduction. International Journal of Disaster Risk Science 6(2): 202-204.

Clark, W.C., T.P. Tomich, M. van Noordwijk, D. Guston, D. Catacutan, N.M. Dickson, and E. McNie. 2011. Boundary work for sustainable development: Natural resource management at the Consultative Group on International Agricultural Research (CGIAR). Proceedings of the National Academy of Sciences 113(17): 4615-4622.
CCAFS (Climate Change, Agriculture and Food Security). 2015. Change for the better: The CCAFS annual report. https://ccafs. cgiar.org/research/annual-report/2015. Accessed 7 May 2016.

Coe, R., F. Sinclair, and E. Barrios. 2014. Scaling up agroforestry requires research 'in' rather than 'for' development. Current Opinion in Environmental Sustainability 6: 73-77.

Danielsen, F., M.K. Sorensen, M.F. Olwig, V. Selvam, F. Parish, N.D. Burgess, T. Hiraishi, V.M. Karunagaran, M.S. Rasmusse, L.B. Hansen, A. Quarto, and N. Suryadiputra. 2005. The Asian tsunami: A protective role for coastal vegetation. Science 310 (5748): 643 .

Doswald, N., and M. Estrella. 2015. Promoting ecosystems for disaster risk reduction and climate change adaptation: Opportunities for integration. Discussion paper, United Nations Environment Programme, Geneva. http://www.preventionweb.net/ publications/view/44969. Accessed 7 July 2016.

EEA (European Environment Agency). 2015. Exploring nature-based solutions - the role of green infrastructure in mitigating the impacts of weather- and climate change-related natural hazards. EEA technical report No 12/2015, Copenhagen. http://www.eea. europa.eu/publications/exploring-nature-based-solutions-2014. Accessed 7 Feb 2016.

EERI (Earthquake Engineering Research Institute). 2009. Learning from earthquakes: The M7.3 September 2, 2009, West Java Quake. EERI special earthquake report. http://www.eeri.org/site/ images/lfe/pdf/WestJavaEQ-9-2-09.pdf. Accessed 27 Oct 2010.

FEMA (Federal Emergency Management Agency). 2013. Federal Emergency Management Agency, Building Science Branch. http://www.fema.gov/building-science. Accessed 17 May 2014.

Geneletti, D., and L. Zardo. 2016. Ecosystem-based adaptation in cities: An analysis of European urban climate adaptation plans. Land Use Policy 50: 38-47.

IFAD (International Fund for Agricultural Development). 2013. Climate Resilient Post-harvest and Agribusiness Support Project (PASP) including blended Adaptation for Smallholder Agriculture Programme Grant (ASAP). http://operations.ifad.org/web/ ifad/operations/country/project/tags/rwanda/1497/documents. Accessed 8 Nov 2016

IPCC (Intergovernmental Panel on Climate Change). 1990. Climate change: The IPCC scientific assessment. Report prepared for Intergovernmental Panel on Climate Change by Working Group I, ed. J.T. Houghton, G.J. Jenkins, and J.J. Ephraums. Cambridge: Cambridge University Press.

Kathiresan, K., and B.L. Bingham. 2001. Biology of mangroves and mangrove ecosystems. Advances in Marine Biology 40: 81-251.

Kelman, I. 2015. Climate change and the Sendai framework for disaster risk reduction. International Journal of Disaster Risk Science 6(2): 117-127.

Manyena, B. 2016. After Sendai: Is Africa bouncing back or bouncing forward from disasters? International Journal of Disaster Risk Science 7(1): 41-53.

Mires, F. 2015. About the correct use of words in politics (Acerca del uso correcto de las palabras en la política). Prodavinci, 16 October 2015. http://prodavinci.com/blogs/acerca-del-uso-cor recto-de-las-palabras-en-la-politica-por-fernando-mires/. Accessed 8 Nov 2016 (in Spanish).

Nature Conservancy. 2015. Urban coastal resilience, valuing nature's role. https://global.nature.org/content/urban-coastal-resiliencevaluing-natures-role. Accessed 26 March 2016.

Parkes, M.W., L. Bienen, J. Breilh, L.N. Hsu, M. McDonald, J.A. Patz, J.P. Rosenthal, M. Sahani, A. Sleigh, D. Waltner-Toews, and A. Yassi. 2005. All hands on deck: Transdisciplinary approaches to emerging infectious disease. EcoHealth 2: 258-272. 
Parker, R., A. Kreimer, and M. Musinghe. 1995. Informal settlements, environmental degradation, and disaster vulnerability: The Turkey case study. Washington: World Bank Group.

Renaud, F., and R. Murti. 2013. Ecosystems and disaster risk reduction in the context of the Great East Japan Earthquake and Tsunami-a scoping study. UNU-EHS Publication Series No.10. https://www.iucn.org/sites/dev/files/import/downloads/kncf_ report_final.pdf. Accessed 22 June 2014.

Renaud, F.G., K. Sudmeier-Rieux, M. Estrella, and U. Nehren (eds.). 2016. Ecosystem-based disaster risk reduction and adaptation in practice. Advances in Natural and Technological Hazards Research 42. Cham: Springer.

Scholz, R.W., and G. Steiner. 2015. The real type and ideal type of transdisciplinary processes: Part II-what constraints and obstacles do we meet in practice. Sustainability Science 10: 653-671.

Stock, P., and R.J.F. Burton. 2011. Defining terms for integrated (Multi-Inter-Trans-Disciplinary) sustainability research. Sustainability 3(8): 1090-1113.
UN (United Nations). 2015. Sustainable development goals. https:// sustainabledevelopment.un.org/. Accessed 27 Aug 2016.

UNFCCC (United Nations Framework Convention on Climate Change). 2015. Adoption of the Paris agreement. Draft decision CP.21. FCCC/CP/2015/L.9/Rev.1. http://unfccc.int/resource/ docs/2015/cop21/eng/109r01.pdf. Accessed 27 Aug 2016.

UNISDR (United Nations International Strategy for Disaster Reduction). 2005. Hyogo framework for action 2005-2015: Building the resilience of nations and communities to disasters. Geneva: UNISDR.

UNISDR (United Nations International Strategy for Disaster Reduction). 2015. Sendai framework for disaster risk reduction 20152030. Geneva: UNISDR.

Wisner, B. 2001. Risk and the Neoliberal State: Why post-Mitch lessons didn't reduce El Salvador's earthquake losses. Disasters 25(3): 251-268. 